Culture et histoire dans l'espace roman

6 | 2011

Figures du pouvoir dans la littérature hispanoaméricaine

\title{
El autoritarismo materno como fundamento del poder patriarcal, en el cuento " Me van a matar » de la colección Mensajes al más allá, de la escritora nicaragüense Irma Prego
}

\section{Milagros Palma}

\section{OpenEdition \\ Journals}

Edición electrónica

URL: https://journals.openedition.org/cher/9537

DOI: 10.4000/cher.9537

ISSN: 2803-5992

Editor

Presses universitaires de Strasbourg

Edición impresa

Fecha de publicación: 30 junio 2011

Paginación: 163-174

ISBN: 978-2-35410-033-9

ISSN: 1968-035X

\section{Referencia electrónica}

Milagros Palma, «El autoritarismo materno como fundamento del poder patriarcal, en el cuento « Me van a matar » de la colección Mensajes al más allá, de la escritora nicaragüense Irma Prego», reCHERches [En línea], 6 | 2011, Publicado el 17 diciembre 2021, consultado el 26 enero 2022. URL: http://journals.openedition.org/cher/9537 ; DOl: https://doi.org/10.4000/cher.9537

\section{(c) (i) (9)}

Ce(tte) œuvre est mise à disposition selon les termes de la Licence Creative Commons Attribution Pas d'Utilisation Commerciale - Partage dans les Mêmes Conditions 4.0 International. 


\title{
El autoritarismo materno como fundamento del poder patriarcal, en el cuento "Me van a matar" de la colección Mensajes al más allá, de la escritora nicaragüense Irma Prego
}

\author{
Milagros Palma \\ Université de Caen
}

\section{La autora y su obra}

Irma Prego (Granada, 1938 - San José de Costa Rica, 2002) es una narradora con una trayectoria poco usual. Poco usual por el momento en que hace pública su creación literaria, por la temática y por su retórica satírica. La escritora nicaragüense proviene de una familia de alto nivel económico. ${ }^{1}$ Estudia en el colegio de monjas. Desde su casamiento, Irma Prego se instala en Costa Rica, tiene cuatro hijos. Al cabo de 25 años de vida conyugal, después de su divorcio, Irma Prego se revela como escritora. Esta tardía vocación, el poeta José Coronel Urtecho la atribuye a sus relaciones de adolescencia:

sin su amistad de colegiala con los jóvenes poetas, no habría sido más que una respetable señora granadina o cumpliendo, como lo hizo, el singular destino que le tenía reservado su horóscopo, una excelente madre de familia costarricense. $^{2}$

1 «De muy reciente origen español», dice en su Introducción, Coronel Urtecho: Ver Mensajes al mas allá, p. 15.

2 Introducción a la colección de cuentos de Irma Prego, Mensajes al más allá, 1989. 
Pero cualquiera que fuese el origen de su vocación o de sus influencias, Irma Prego es una de las pocas narradoras de su país que además trata con humor duro y con sarcasmo el tema de la vida conyugal.

La obra de Irma Prego se compone de 35 cuentos y viñetas reunidos en dos colecciones. Los temas de Irma Prego desde esta primera colección son la vida doméstica, la formación heterosexual de la niña, el encuentro amoroso o punto inicial del intercambio económico-sexual (heterosexual), la vida conyugal (trabajo sexual y reproductivo y la separación. El hombre abandona por lo general a la pareja en busca (de nueva prestataria de servicio sexual por lo general de estatus social y económico inferior) de la mujer complaciente y disponible, por lo general más joven y de medio social más bajo que el suyo.

Originalmente en esta primera colección debía figurar el monólogo Agonice con elegancia que es texto emblemático en el cual Irma Prego alcanza su máxima virtuosidad satírica. Consciente del carácter testimonial y autobiográfico de la obra, Coronel que hace un prefacio que no tiene nada que ver con la obra, sucumbe al dilema de la apariencia y la realidad: ¿cómo es posible que un matrimonio que parecía feliz pudiese haber vivido en un infierno tan grande?; como ya decía el escritor colombiano Gabriel García Márquez: "No hay infierno más grande que un matrimonio feliz» en las primeras líneas de su monólogo Diatriba de amor contra un hombre sentado (1995). Sin embargo, la educación tradicional de Coronel Urtecho le impide reconocer la novedad de la obra de Prego y califica el monólogo Agonice con elegancia de demasiado "autobiográfico o confesional».

La segunda colección de Irma Prego se encuentra inédita. En esta colección la escritora nicaragüense da una visión de los mecanismos de la violencia real y simbólica necesarias a la imposición de una serie de normas y comportamientos sexuados orientados a garantizar las relaciones de subordinación femenina y de dominación masculina en vista de un intercambio económico-sexual que linda con una suerte de esclavitud de la mujer. En la regulación de los géneros, el control que ejerce la madre y los varones de la familia en la niña es fundamental para su formación heterosexual. La desvalorización y sobre todo la negación y diabolización de la pulsión parcial y total y de la práctica del placer orgásmico aparecen como los objetivos primordiales para asegurar la docilidad necesaria al sometimiento de la mujer a la actividad coital en el espacio privado.

En los cuentos de Irma Prego el papel materno consiste en reproducir las bases de un orden que garantice el placer sexual del hombre con 
la construcción de la heterosexualidad que supone el servicio sexual incondicional de la mujer, el uso de su cuerpo para el placer y para el trabajo de fecundación y de reproducción de la especie ya que sexualidad y fecundación se encuentran conectados en el sujeto de sexo masculino.

En el cuento Me van a matar podremos descubrir cómo se forma, se especializa y se deserotiza a la niña para que una vez adulta pueda integrar de manera espontánea, casi natural, el circuito económico-sexual que le permita asegurar su supervivencia, desempeñando un servicio sexual para el trabajo reproductor y materno. Es gracias a la imposibilidad de explorar, descubrir, elaborar una sexualidad propia, que se condiciona a la mujer para la subordinación y la dependencia. Fuera del coito no existe una actividad sexualidad propia para la mujer.

\section{¿Por qué el título Me van a matar?}

Nada mejor que el testimonio de la autora a quien tuve la oportunidad de entrevistar al respecto. He aquí su respuesta:

Mi mamá solía decirnos todo el tiempo "Me vas a matar" por todo. Por una nota: "Me vas a matar". Por un vaso quebrado: "me vas a matar". Por una pelea con los hermanos varones: "me vas a matar".

«¿Y eso que significación tenía?»:

Realmente yo vivía aterrorizada, de pensar que podía matar de veras a mi mamá. Porque además era hipocondríaca y siempre le estaba doliendo algo, o se iba a morir del corazón o del hígado. Toda mi infancia me la pasé rezando con el terror de matarla.

Pero no sólo era el terror cotidiano el que mantenía a Irma en un estado permanente de inseguridad, de miedo, de culpa sino que además había un maltrato físico muy grande.

Con esta respuesta y la expresión «Mi mamá solía» es evidente deducir que se trata de un relato inspirado en la experiencia de la vida de infancia de la autora como lo podremos corroborar más adelante.

« ¿Tu mamá te maltrataba?»

Ella me flagelaba. Tenía dos coyundas guindadas en un poste.

Entonces cuando me daba esas flageladas me quedaban los verdugones rojos que se me hacían morados. Me pasaba días de días con la cicatriz y los cardenales y eso me ponía muy avergonzada en el colegio; me subía las medias hasta arriba para que no me vieran con los verdugones colorados. 
El verbo flagelar es utilizado en el cuento, lo mismo que los detalles en cuanto a los cambios que sufre la piel con los hematomas que pasan del rojo al morado, y las cicatrices. La vergüenza que siente resulta del hecho de ser cuestionada en la escuela. Esto mismo le sucede al personaje del cuento, Nena.

A la pregunta: «La manera de educarte de tu mamá ¿era especial o más bien común en Nicaragua?», ella responde así:

Después platicando con gente mayor y menor que yo me di cuenta que ese es el método de educación en Nicaragua. Y esto en las familias que más o menos aprendieron a leer y a escribir. No voy a hablar de cultura porque a una amiga que es diez años menos que yo, la mamá le hacia iniquidades como la mía a mí.

Una señora mayor me decía que su abuela que la crió vivía diciendo así "me vas a matar" por todo. Mi nana me decía lo mismo.

Pienso que es un recurso desesperado de dominación de la madre a la hija, de la nana a la chiquita que cuida.

Los diferentes ejemplos en cuanto a generaciones, y medios sociales nos permiten deducir que "el chantaje afectivo" era una generalidad.

Y para hacerla situar esta costumbre en su contexto le hice la siguiente pregunta: «¿Pero eso era de tu época?».

Se sigue usando todavía. Es probable que en Nicaragua si tú preguntas, la gente te lo va a decir. Estos eran los métodos de educación. No existía la psicología. Los hogares eran totalitarios.

Aquí Irma Prego nos entrega una serie de testimonios que le permiten concluir que se trata de un sistema generalizado de maltrato de la madre hacia la hija.

Con frecuencia en los textos de mujeres, se habla de la relación madrehija, el padre aparece muy poco. Yo le pregunté a Irma Prego cómo era su padre y qué papel jugaba en esta relación despótica maternal.

Ella era totalitarísima con papá y con todo el mundo. O sea que ella le daba orden a papá para que actuara. Así llueva o truene. Él era un hombre muy bueno. Sabía perfectamente bien que ella tenía un carácter tremendo y prefería no enfrentarla sino hacerse el sonso, era silencioso, y trataba eso con gran indiferencia. Pero ella mangoneaba la situación.

«¿Él le pegaba a ella?»:

No, nunca jamás. Era un hombre muy suave, muy bien educado pero si tomaba tragos, que con frecuencia lo hacía, los fines de semana, había que oír el vozarrón. ¡Que me alisten el baño. Clara saca a todo el mundo! y todo el mundo aterrado. 
Si claro todo el mundo asustado y las tías también porque se iba a visitarlas. Él con mucho trago y las tías solteras se morían de miedo. "Allí viene Julio con tragos porque se ponía malcriado". Ahí se sacaba el clavo con todo el mundo. Le cambiaba muchísimo el carácter, era otra persona y claro cuando papá murió para mamá fue demasiado porque mal que bien ella siempre me estaba amenazando.

La expresión «trago» en singular y en plural, significa en Nicaragua beber alcohol. Aquí el alcoholismo del padre (todos los fines de semana que regresaba de la hacienda) tenía como consecuencia "el maltrato familiar" de su esposa, de sus hermanas solteras como nos lo permiten constatar las expresiones: cambio de carácter, vozarrón, mala crianza, sacarse el clavo y el efecto que producían: el terror de las tías, de la madre, es decir de las mujeres de la familia.

La madre de Irma Prego reunía los peores defectos, «de carácter tremendo, manipuladora» y para colmo «totalitaria». La palabra totalitaria viene de total. La madre ejerce un control total.

Nada anormal que la niña sienta un rechazo hacia la madre, un odio, diría Freud, una hostilidad diría la psicoanalista Hélène Deustch que además lo corrobora:

la madre impide a la niña volverse adulta. Ella está al servicio de la especie. Hay una suerte de infantilización permanente de la madre hacia la niña. Ella es la que la mantiene en una suerte de infantilismo. No es sujeto de deseo ya que es considerada como una función biológica. De ahí su conducta cruel, violenta.

Por lo general los varones niños y adultos, al contrario de niñas y mujeres, tienen una imagen totalmente opuesta de la madre, por su suavidad, su amor, el esmero en sus cuidados, por su capacidad de despertar el erotismo del futuro adulto, hasta tal punto que ninguna mujer la iguala. Ella es única y no sólo, según parece, el hombre «andaría siempre en busca de una madre servidora, dispuesta al sacrificio de su hijo».

En estos mismos testimonios hemos podido observar que la autora tiene una gran simpatía hacia el padre. El padre es recordado con empatía, merece todos los adjetivos positivos: bueno, muy suave, muy bien educado, le encantaba platicar conmigo, contarme cuentos, hacerme prodigios. Sin embargo si no nos hubiera dado algunos rasgos sobre su comportamiento, lo hubiéramos creído.

Para la autora el único defecto del padre era su alcoholismo porque cuando él tomaba tragos era malcriado. Gritaba. Las tías se morían de 
miedo. El carácter le cambiaba por completo. Era otra persona. En palabras más modernas podríamos decir un border line.

No es por casualidad que Caroline Eliacheff et Nathalie Heinich, en su «Avant propos» del libro Mères-filles une relation à trois, hablen de lo acaparante que resulta esta relación:

Les hommes ne le savent peut-être pas, mais ce dont la plupart des femmes préfèrent parler entre elles, ce n'est pas d'eux : c'est de leur mère. Tant et tant de confidences, chuchotées entre filles, entre adolescentes, entre femmes, adultes, entre mères, entre grand-mères même tournent autour des faits et des dits de leur mère, c'est que le sujet est un universel féminin (11).

Es precisamente del maltrato de la niña y la razón de ello que trata el cuento de Prego. En efecto en el relato Me van a matar la madre vigila rigurosamente a sus hijas hasta en su más oculta intimidad. Se trata de un espionaje minucioso cuyo objetivo consiste en impedir cualquier manifestación de placer ya sea de la pulsión parcial y sobre todo de la pulsión total. El término pulsión es un elemento mítico del fundamento del saber de Freud ${ }^{3}$.

En la formación de la niña está en primer lugar el control de toda pulsión parcial y sobre todo la total. Las pulsiones se presentan como una tensión, una excitación corporal: liberar esa tensión produce placer. Los gestos más íntimos son controlados y censurados como veremos más adelante.

En el cuento Me van a matar, un narrador omnisciente cuenta la historia de una mujer devota, madre de cuatro hijos, dos varones y dos mujeres, de familia terrateniente de Granada, ciudad de tradición conservadora, en Nicaragua. Esta madre, a quien raras veces se le escapaba una sonrisa, tal era su férreo control ya que la más mínima expresión de placer de la pulsión parcial era considerada como una debilidad. Su objetivo primordial en la vida era sufrir para alcanzar la santidad y gozar en el más allá. Un día de tantos la mujer de Moncada queda viuda, es decir que se vuelve la viuda Moncada.

3 Para Freud es una irrupción de energía vital que se ejerce en los organismos animados. Sin embargo hay una gran diferencia entre los seres vivos y los seres humanos: en los seres vivos, esta irrupción de energía conserva la opacidad biológica del instinto. Para los seres vivos la pulsión está regulada de una vez por todas, es automática e irreprensible. Mientras que en el ser humano se transforma en representaciones síquicas destinadas a diferenciarse poco a poco. En los seres humanos la pulsión no supone coacción absoluta: dormir, comer, beber son vitales mientras que copular no lo es. Ello obedece a un deseo más que a una necesidad (Jean Bellemin-Noel). 
El padre muere fulminado por una peritonitis.

Con la muerte del padre la actividad religiosa de la viuda va a ser aún más intensa: "Se acrecentaron las devociones a los santos y las novenas a las vírgenes de todas las devociones y al rezo del santo rosario que era una devoción cotidiana».

Estas enumeraciones, dan una idea de la vida religiosa de un país como Nicaragua. País que como la mayoría de los países hispanos, es consagrado a la Virgen de la concepción, la Virgen que engendra4. "La madre con el iris verde jade y cornea blanquísima volteaba sus ojazos hacia el infinito, caía aparatosa de rodillas en cualquier rincón de la casa y oraba compungida».

La viuda de Moncada pertenece a una clase alta a la cual alude el calificativo "verde» de sus ojos, y por lo tanto no está sola en el trabajo doméstico, tiene varias empleadas: la Carmen en la plancha, la Lucila que era nodriza y la encargada de la limpieza de la cual no se conoce el nombre. Todas ellas la acompañaban en su actividad religiosa.

Pero de manera paradójica esta mujer vivía con cierta frustración como lo constata el narrador: "El carácter se le fue agriando cada vez más ».

El verbo «agriar» alude a una descomposición que como en el vino o la leche es hasta útil porque de ello resulta otro producto que es el vinagre, o el yogur. Lo mismo sucede con la pulsión, de ahí el dicho : el vinagre es al vino lo que la frustración es a la pulsión. Con su mal carácter, sus métodos represivos se fueron endureciendo aún mas. Lo cual es normal cuando no se tiene sexualidad. De ahí la angustia o los efectos de la posesión diabólica de las mujeres, o de la histeria en el siglo XIX.

Sin embargo lo importane en este momento de narración es la puesta en escena del hijo mayor, que aparece en una alianza contra las hijas: "asesorado por su hijo mayor», el preferido de ella, el que asumió las funciones de padre.

4 La virginidad de María ha sido objeto de grandes discusiones entre teólogos, historiadores, creyentes como los curas, para corroborar, dar fe del fenómeno de la virginidad ya que fue fecundada por Dios, un ente virtual. La iconografía religiosa da cuenta de ello con el famoso cuadro de Boticcelli donde el arcángel san Gabriel le anuncia que ha sido fecundada. Es decir que para ella todo fue facíl ya que no tuvo que pasar por ese servicio. Sin embargo la virginidad parece aludir al hecho de no haber tenido ningún placer ya que es el placer propio de la sexualidad femenina el que hace que se condene a la mujer. Eva peca porque goza, sola, porque descubre que viene dotada de un órgano especializado en el placer puro sin conección alguna con la reproducción. 
Con un hijo quien a su vez era no sólo despótico sino sobre todo sicótico, un hombre enfermo quizá por su ocupación en una función autoritaria quizá demasiado prematura va a impedir cualquier rescoldo de placer en las niñas.

La viuda se va a dotar de herramientas de tortura cuando entra en función para asegurar la educación de su prole.

No más pasado el funeral y los nueve días de su esposo, guindó en un poste de la cocina dos coyundas una de cuero y otra de cuero más blando... hasta de cuatro cinturas gruesas.

Con estos instrumentos la madre asume su nueva función de única correctora de sus hijos varones y de sus hijas mujeres: «Les descargaba sobre piernas y brazos y espalda de sus hijos».

Todo sería normal si no hubiera un tratamiento específico según el sexo de su progenitura ya que las niñas se sentían mal consideradas, de manera injusta por la madre: «las creía capaces de una anomalía o perversidad».

Para los términos "anomalía o perversidad», el diccionario indica: desconfianza, sospechas, que van a desencadenar una suerte de control paranoico en torno a sus adolescentes: «como una vigilancia totalitaria».

La palabra "totalitaria» alude a un sistema en el cual el margen de movimiento de las personas es mínimo. El usual toque de queda va acompañado de la prohibición de reuniones en las calles y sobre todo de requisiciones en casas.

La desconfianza estaba sobre todo orientada hacia Nena, la menor, por su curiosidad y por su buen humor: «Nena era viva de genio, independiente, de alegre carácter y pronta a la risa».

Estas cualidades hacían de ella un peligro en la vida. Por eso hay control riguroso. La madre les impedía salidas y todo lo que pudiera favorecer su autonomía como el dinero y que pusiera en peligro su honor, su virginidad. $\mathrm{Su}$ comportamiento es catalogado por el narrador como un espionaje minucioso: "Las vigilaba sin piedad hasta en su más recóndita intimidad».

El control de la madre estaba orientado a impedir el acceso al conocimiento de las zonas erógenas de su cuerpo.

Se trataba de impedirles una desviación en cuanto a su destino reproductor biológico. Si ellas lograran conocer el funcionamiento de la sexualidad y del placer eso podría poner en peligro la sumisión necesaria para asegurar la dependencia obligatoria al intercambio económico-sexual necesario al 
placer orgásmico del hombre y la fecundación y trabajo reproductor de la hembra humana.

Asegurar la reproducción biológica y por consiguiente que estuvieran conformes a los valores religiosos en donde el placer orgásmico era considerado como diabólico, era una de las mayores exigencias de la viuda para con sus hijas y eso suponía acostumbrarlas al sometimiento a través de la dominación que va a ejercer el varón.

Las chicas sentían una suerte de impotencia total. No sabían cómo revelarse porque el control era sobrehumano. En un encierro total. La sexualidad que es insinuada a través de expresiones religiosas como lo expresa el campo léxico del pecado, era tratada como algo diabólico.

Para que no se le ocurrieran malos pensamientos, es decir para que no se les ocurriera asociar el deseo con una práctica del placer, sus rezos estaban orientados a exorcizar ese terror: «ilumínalas señora para que abominen el besuqueo y el toqueteo pues vos sabés que quien da el pico da el mico».

La expresion «quien da el pico da el mico» alude al hecho de una supuesta liviandad femenina. Como la joven no sabe nada acerca de su sexualidad, como tampoco no sabe gran cosa sobre el coito que es acto de placer para el hombre ella se va a someter en espera de ese placer. Un beso (pico) puede hacerle perder la viriginidad (el mico). La palabra mico significa mono. El mico a su vez es un eufemismo para evocar los genitales femeninos que tienen otros nombres asociados con la suciedad como «la cucaracha»o «el bicho».

A pesar de la manera autoritaria y violenta con la cual forma la viuda a sus hijas, no podemos decir que no quiere a sus hijos. Es de esa manera que ella quiere a sus hijas para asegurar su seguridad y conformidad a las normas de género. Por lo general la mujer va al cielo cuando permanece sin orgasmar. Es decir que se ha sometido al servicio sexual y ha permanecido anestesiada al placer sexual.

Para impedir "el mal paso», la afrenta de familia o pecado de la carne, el pecado mortal, nada mejor que la religión: «A ti celestial princesa, virgen sagrada María, te entrego alma, vida y corazón y a estas hijas mías que son mi gran ilusión».

Frente a esta educación las niñas sólo pueden sentir impotencia por la manera como son tratadas.

La ignorancia de las niñas y el maltrato físico y psicológico son las bases ideales que contribuyen a la consolidación de las relaciones de sometimiento 
necesario al intercambio económico sexual o práctica heterosexual. Para dejarlas en la total dependencia, les impidió todo acceso a la educación formal:

"A las hijas no, a esa profesión no", decía la viuda. "Dios no le dio alas al animal ponzoñoso. Ajaa..., mis alacrancitas, las llamaba para explicarles que la madre alacrana es devorada siempre por sus crías recién nacidas, las que sólo dejan el cascarón pues hambrientas le comen sus entrañas.

La educación formal que se les niega y se les prohibe a las niñas es sin embargo promovida para los varones. La profesionalización consagra su superioridad: mientras varones gozan de libertad y del desarrollo necesario para funcionar en la sociedad de manera autónoma, «Ella les fomenta el machismo».

Para ello, les armaba toda clase de intrigas con sus hermanos para que salieran en su defensa porque ella aparecía siempre como víctima de sus hijas.

Con sus chantajes se vuelve el centro de muchas atenciones por parte de sus hijos:

Algunas veces los hijos armaban unas grescas tremendas entre ellos o contra las hermanas, a las que trataban a lo bestia. La madre encontraba que la brutalidad de sus adolescentes era hombría consustancial a su sexo y así les fomentó un machismo ultramontano, a tal grado que cuando tenían que alternar en compañía femenina no sabían cómo actuar.

Del trato «a lo bestia», es decir inhumano, participan de manera servil los hermanos varones que gozan de un tratamiento valorizante, viril.

Ignorancia, represión sexual, desvalorización, son la base de la educación femenina. Es así como las jóvenes buscan cómo encontrar a un hombre que las salve de la precariedad y sufrimiento en el que viven.

En los personajes de Irma Prego, la frustración se encuentra naturalizada e interiorizada. En ellas domina la confusión. Entre más maltrato por parte del hombre más sometimiento e incondicionalidad obtiene como suele hacerse con la domesticación de un animal de compañía.

Tratándose de un cuento inspirado en la realidad, la escritora nos dice:

Ella me llevaba a todas sus actividades religiosas, me llevaba de la rechinga a comulgar, a rezar. Mi relación con ella fue muy difícil. A los tres varones ella los destinó para que vivieran y fueran profesionales, pero Irma tenía que quedarse con ella hasta el último día de su vida. La desaprobación de mi mamá para todo lo mío fue sistemática. Mis intereses, mis aficiones. Todo 
me lo desaprobaba tremendamente. Huyendo de ella a Costa Rica me casé en tres meses.

\section{Conclusión}

El antropólogo francés, Levi-Strauss en su artículo «Sexualidad femenina y origen de la sociedad», confirma que la pérdida del estro en la hembra animal anuncia el origen de la hembra humana.

Esta revolución biológica pone en peligro la supervivencia de la nueva especie humana. La hembra humana aparece dotada de un órgano del placer desconectado de la reproducción. En ella sexualidad y reproducción son dos cosas diferentes, sin embargo el macho conserva su morfología animal. Sexualidad y reproducción están conectados. El macho humano necesita orgasmar para poder eyacular y fecundar.

Pero lo que caracteriza al ser humano es su aptitud a simbolizar, de allí el lenguaje. La aparición del lenguaje consolida la humanidad. Sin embargo la gran prioridad de ese momento de trastorno del programa reproductivo va a consistir en construir un programa cultural que asegure la reproducción de la especie humana. Es decir programar a la hembra humana para que se someta a la fecundación, al coito del macho humano.

Mucho, mucho tiempo ha pasado, siglos de siglos amén, y antropólogos como Paola Tabe, N.Cl. Mathieu, P. Bourdieux entre otros, dan cuenta de la inhibición de la sexualidad femenina, transformada en servicio sexual. De ahí las mutilaciones en las sociedades tribales que aún existen en Africa y en algunas tribus amazónicas que representan más de 200 millones de mujeres mutiladas sexualmente.

¿Cual es el condicionamiento para que la hembra humana se someta al servicio sexual en las sociedades civilizadas? Impedir a la hembra el conocimiento de su deseo y de su sexualidad propia, ya que entre la sexualidad femenina y la reproducción no existe conección. Todo lo contrario de la sexualidad del macho humano que está conectada con la función reproductora. El orgasmo es necesario a la fecundación. El coito se vuelve el acto sexual por excelencia. Como en la reproducción animal. Por eso impedir el conocimiento del cuerpo y además del saber en general es $y$ ha sido un instrumento del poder masculino. Y sobre todo, de un trabajo permanente de violencia real y simbólica para hacer de la mujer un objeto. Este es el condicionamiento del que da cuenta el cuento Me van a matar de la escritora nicaragüense Irma Prego. 
El sociólogo Pierre Bourdieux ya lo había señalado en su libro $L a$ dominación masculina: la sexualidad es una relación de poder masculino y sometimiento femenino.

\section{Bibliografía}

Prego, Irma, 1989, Mensajes al mas allá, Managua, Editorial Nueva Nicaragua.

Bellemin-Noel, Jean, 1996, La psychanalyse du texte littéraire, Introductions aux lectures de critiques inspirées par Freud, Paris, Nathan. 